УДК $581.192-577.151$

\title{
ВЛИЯНИЕ УСЛОВИЙ ОБРАБОТКИ НА ВЫХОД И СОСТАВ ПРОДУКТОВ ФРАКЦИОНИРОВАНИЯ СОЛОМЫ ПШЕНИЦЫ В СРЕДЕ ХЛОРИДА 1-БУТИЛ-3-МЕТИЛИМИДАЗОЛИЯ
}

\author{
(C) С.Н. Евстафьев", К.К. Хоанг
}

\author{
Иркутский национальный исследовательский технический университет, \\ ул. Лермонтова, 83, Иркутск, 664074 (Россия), e-mail: esn@istu.edu
}

Работа посвящена выявлению влияния температуры и продолжительности обработки соломы пшеницы в среде хлорида 1-бутил-3-метилимидазолия на выход и состав фракций ее основных компонентов. Установлено, что с повышением продолжительности и температуры обработки в интервале $100-150{ }^{\circ} \mathrm{C}$ происходит очистка целлюлозы от гемицеллюлоз и лигнина. Выявлено, что процессы делигнификации достаточно интенсивно протекают до $120^{\circ} \mathrm{C}$. В составе фракции целлюлозы содержание лигнина снижается до $17-18 \%$ и нарушается прочность водородных связей. Все это в комплексе приводит к существенному повышению реакционной способности целлюлозы в условиях ферментолиза. Максимальный выход сахаров из полисахаридов соломы пшеницы (60,8\% на а.с.м.) получен после ее обработки в среде хлорида 1-бутил-3-метилимидазолия при $140{ }^{\circ} \mathrm{C}$ в течение 2 ч.

Ключевые слова: солома пшеницы, ионная жидкость, 1-бутил-3-метилимидазолия хлорид, целлюлоза, гемицеллюлозы, лигнин, ИК-спектроскопия.

\section{Введение}

В последние годы интерес к использованию ионных жидкостей (ИЖ) в качестве «зеленых растворителей» для разделения лигноцеллюлозных материалов возрастает [1]. ИЖ, обычно состоящие из больших органических катионов и небольших неорганических анионов, существуют в жидком состоянии при относительно низких температурах, часто при комнатной температуре. Для них характерны высокая химическая и термическая стабильность, негорючесть и низкое давление паров, что дает возможность проводить с достаточно высокой эффективностью обработку лигноцеллюлозного сырья при атмосферном давлении и относительно низкой температуре.

Предполагают, что растворение лигноцеллюлозы в ИЖ обусловлено нарушением в ее составе внутри- и межмолекулярных водородных связей и образованием новых между анионом ИЖ и поверхностными гидроксильными группами полисахаридов [2]. Ряд исследователей [3] считают, что в образовании водородных связей с полисахаридами участвуют и катионы ИЖ, повышая тем самым их растворимость.

Многие ионные жидкости, представляющие собой соли соляной, фосфорной, муравьиной и уксусной кислот, использованы для растворения лигноцеллюлозного сырья и показали при этом достаточно высокую эффективность. [2, 4]. Среди них определенный интерес представляют соли 1-алкил-3метилимидазолия. Катион имидазолия не содержит атомов с высокой электроотрицательностью и тем самым не вызывает снижения эффективности сольватации. Имея небольшие размеры, он не создает пространственных затруднений при формировании межмолекулярных водородных связей. Высокую эффективность при фракционировании биомассы соломы пшеницы показали ацетат 1-этил-3метилимидазолия [5] и хлорид 1-аллил-3-метилимидазолия [6]. При этом было установлено, что анион хло-

Евстафьев Сергей Николаевич - доктор химических наук, профессор, директор, e-mail: esn@istu.edu Кыонг Хоанг Куанг - аспирант, e-mail: hqc9189@gmail.com ра, имея небольшие размеры, является более эффективным в разрушении междумолекулярных водородных связей лигноцеллюлозы в сравнении с ацетатионом. Таким образом, немногочисленные литера-

\footnotetext{
* Автор, с которым следует вести переписку.
} 
турные данные позволяют предположить возможность эффективного использования хлорида 1-бутил-3метилимидазолия для фракционирования лигноцеллюлозного сырья. На сегодняшний день информация об использовании этой ИЖ для обработки соломы пшеницы в литературе отсутствует.

Целью работы являлось изучение влияния температуры и продолжительности обработки на выход и состав продуктов фракционирования соломы пшеницы в среде хлорида 1-бутил-3-метилимидазолия.

\section{Экспериментальная часть}

В работе использовали образцы обессмоленной соломы пшеницы крупностью менее 0,5 мм. Компонентный состав соломы, в процентах на абсолютную сухую массу (на а.с.м.): целлюлоза 42,85; лигнин 25,72 ; гемицеллюлоза 30,1. Для удаления экстрактивных веществ солому экстрагировали в аппарате Сокслета в течение 12 ч. Непосредственно перед экспериментом ИЖ и обессмоленную солому сушили в вакууме при $40{ }^{\circ} \mathrm{C}$ в течение 24 ч.

Обработку соломы проводили в стеклянном стакане емкостью $50 \mathrm{~cm}^{3}$, помещенном в термостат, при непрерывном перемешивании смеси механической мешалкой. Использовали соотношение массы соломы к массе ИЖ, равное $1: 20$. Эксперимент выполнен при температурах 100, 120,140 и $150{ }^{\circ} \mathrm{C}$, продолжительность обработки варьировали от 1 до 7 ч.

Фракционирование лигноцеллюлозного комплекса соломы выполнено по схеме, приведенной на рисунке 1 .

После термической обработки к полученному раствору соломы в ИЖ небольшими порциями добавляли $40 \mathrm{~cm}^{3}$ раствора $0,1 \mathrm{M} \mathrm{NaOH}$ для осаждения растворенной целлюлозы, которую затем выделяли совместно с нерастворенной при термообработке частью соломы центрифугированием при $20{ }^{\circ} \mathrm{C}$ в течение 7 мин на центрифуге Thermo SCIENTIFIC при скорости вращения 10000 об/мин. В результате центрифугирования получали фильтрат и твердую часть.

Для отделения остатков ИЖ твердую часть промывали дистиллированной водой до рН, равного 6-7, а затем экстрагировали $3 \%$ раствором $\mathrm{NaOH}$ в соотношении $1: 35\left(\right.$ г/см $\left.{ }^{3}\right)$ при $50{ }^{\circ} \mathrm{C}$ в течение 45 мин для очистки от осажденных вместе с целлюлозой примесей гемицеллюлозы и лигнина. После экстракции промывали дистиллированной водой до нейтральной реакции и сушили до постоянной массы при $60{ }^{\circ} \mathrm{C}$. Полученный щелочной раствор и промывные воды объединяли с фильтратом, что позволило существенно сократить потери фракций лигнина и гемицеллюлоз в сравнении со схемой фракционирования, опубликованной в работе [5].

Воду из фильтрата удаляли при пониженном давлении до объема $30 \mathrm{~cm}^{3}$. После снижения рН до 6,8 с помощью $1 \mathrm{M}$ раствора $\mathrm{HCl}$ тремя объемами этанола осаждали фракцию гемицеллюлозы, которую затем выделяли центрифугированием и многократно промывали спиртом. Спиртовую промывку объединяли с раствором, из которого была выделена гемицеллюлоза. После удаления спирта вакуумной дистилляцией снижали $\mathrm{pH}$ полученного раствора до 2,0 раствором $0,1 \mathrm{M} \mathrm{HCl}$ и выдерживали при $70{ }^{\circ} \mathrm{C}$ в течение 30 мин. Осажденный лигнин отделяли центрифугированием и промывали $10 \mathrm{~cm}^{3}$ раствора 0,02 $\mathrm{M} \mathrm{HCl} \mathrm{от} \mathrm{остатков} \mathrm{ИЖ.}$

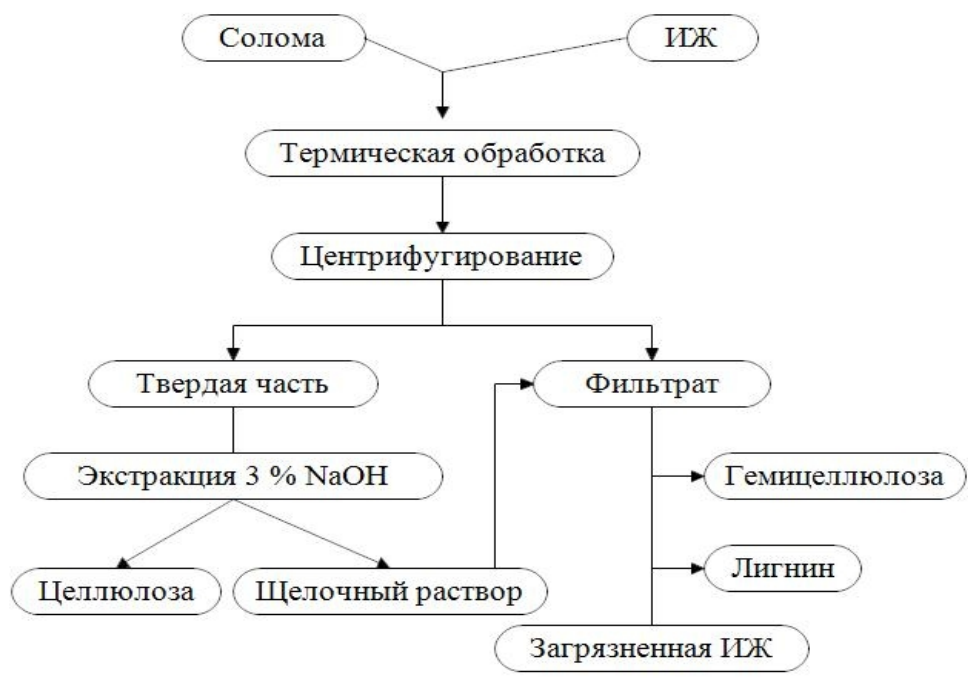

Рис. 1. Схема фракционирования продуктов термообработки соломы пшеницы в среде ионной жидкости 
Фракции целлюлозы и гемицеллюлозы для ферментолиза измельчали в шаровой мельнице до размера менее 0,4 мм. Ферментолиз проводили с использованием ферментного комплекса «Целлолюкс-А» с целлюлазной активностью 2000 ед/г (ПО «Сиббиофарм») при температуре $50{ }^{\circ} \mathrm{C}$, при рН 4,7-4,8 (ацетатный буфер) и интенсивном перемешивании реакционной среды со скоростью 100 об/мин. Концентрация ферментного препарата в реакционной среде $2,5 \mathrm{мг} / \mathrm{cm}^{3}$, отношение массы субстрата к массе раствора составляло $1: 20$. После гидролиза колбу с продуктами гидролиза нагревали до $90^{\circ} \mathrm{C}$ на водяной бане в течение 15 мин, чтобы денатурировать ферменты. По окончании гидролиза субстрат отделяли от гидролизата фильтрованием. Выход редуцирующих сахаров определяли фенол-сернокислотным методом [7].

Элементный анализ выполняли на анализаторе Vario MICRO CUBE. Для количественного определения метоксильных групп использовали метод Цейзеля, фенольных ОН-групп - спектрофотометрический метод [8].

Для определения карбоксильных групп фракцию лигнина метилировали диазометаном в диэтиловом эфире и затем определяли общее содержание метоксильных групп. Количественное содержание карбоксильных групп рассчитывали с учетом содержания в исходных фракциях лигнина метоксильных и фенольных ОН-групп.

Содержание лигнина во фракциях целлюлозы определяли как сумму кислотонерастворимого и кислоторастворимого лигнина по методике [9]. Смесь 350 мг фракции целлюлозы и 3 см $^{3}$ 72\% серной кислоты выдерживали при $30{ }^{\circ} \mathrm{C}$ в течение 1 ч. Затем приливали $84 \mathrm{~cm}^{3}$ дистиллированной воды для получения $4 \%$ раствора серной кислоты и выдерживали при $121^{\circ} \mathrm{C}$ в течение 1 ч. Смесь фильтровали через предварительно взвешенный стеклянный фильтр. Содержание кислоторастворимого лигнина (ASL) определяли методом УФ-спектроскопии по поглощению при 205 нм по формуле:

$$
\operatorname{ASL}(\%)=\frac{n}{k \cdot l} \cdot \frac{V}{m} \cdot 100
$$

где $n$ - оптическая плотность; $k$ - коэффициент поглощения, равный 94,5 л/г·cм; $l$ - оптическая ширина кюветы; $V$ - объем фильтрата, л; $m$ - масса образца, г.

Содержание кислотонерастворимого лигнина (AIL) рассчитывается по весу твердого остатка и золы соломы по формуле:

$$
A I L(\%)=\frac{m_{1}-m_{2}}{m} \cdot 100
$$

где $m_{1}$ - масса твердого остатка, г, $m_{2}$ - масса золы, г, $m$ - масса образца, г.

\section{Обсуждение результатов}

На начальной стадии эксперимента об эффективности процесса фракционирования судили по выходу фракций основных компонентов биомассы соломы в сравнении с их содержанием в исходном образце.

Установлено, что растворение соломы в ИЖ при термообработке зависит от условий процесса. В интервале температур 100-120 ㄷ при продолжительности обработки до 2 ч образец соломы растворяется не полностью. Полученная смесь имеет желтый цвет и содержит визуально наблюдаемые нерастворенные частички соломы, которые при последующей обработке щелочью осаждаются совместно с растворенной частью целлюлозы (рис. 1). При более высоких температурах обработки были получены гомогенные растворы соломы в ИЖ светло-коричневого цвета.

Согласно полученным данным (рис. 2), повышение температуры обработки соломы в среде ИЖ способствует разрушению лигноуглеводного комплекса и, как следствие, сопровождается снижением выхода фракции целлюлозы и увеличением выхода фракций гемицеллюлозы и лигнина.

Следует сказать, что при фракционировании биомасса соломы перераспределяется не только по трем фракциям (рис. 1), но и частично остается в ионной жидкости. При повышении температуры и продолжительности обработки величина этих потерь возрастает (рис. 2). Так, при продолжительности 1 ч с повышением температуры в интервале $100-150{ }^{\circ} \mathrm{C}$ она возрастает с 11,9 до 16,5\%, а при продолжительности 5 ч $\left(140{ }^{\circ} \mathrm{C}\right)$ составила около $39 \%$ на а.с.м. соломы. 
Выход фракции целлюлозы при $100{ }^{\circ} \mathrm{C}$ (1 ч) составил $62,3 \%$ на а.с.м., что почти на $20 \%$ выше содержания целлюлозы в исходной соломе. В составе примесей фракции содержится лигнин в количестве $18,5 \%$ на фракцию. Таким образом, степень делигнификации соломы в этих условиях составила $55,3 \%$ и большая часть лигнина исходной соломы выделилась, вероятно, в составе фракции гемицеллюлозы.

Повышение температуры обработки до $120^{\circ} \mathrm{C}$ существенно не повлияло на результаты фракционирования. Выход фракции целлюлозы снизился до $60,6 \%$, а степень делигнификации увеличилась лишь на $1,0 \%$. Заметное снижение выхода фракции целлюлозы было получено при температурах выше $120^{\circ} \mathrm{C}$, вероятно, как следствие полного растворения образца соломы в ИЖ. При $150^{\circ} \mathrm{C}$ он составил $49,04 \%$ на а.с.м., что выше содержания целлюлозы в исходной соломе не более 7\%. Содержание лигнина во фракции снизилось до 17,2\%, а степень делигнификации соломы увеличилась до 67,0\%.

Лигноуглеводный комплекс соломы пшеницы достаточно устойчив к обработке в среде ИЖ при $120{ }^{\circ} \mathrm{C}$ (рис. 3). С повышением времени обработки до 7 ч выход фракции целлюлозы снижается, но выделенная при этом целлюлоза содержит большое количество примесей. Выход фракции целлюлозы, близкий к содержанию ее в исходной соломе, получен при обработке соломы в течение 2 ч при $140{ }^{\circ} \mathrm{C}$. Увеличение продолжительности до 5 ч, как и температуры до $150^{\circ} \mathrm{C}$, сопровождается разложением как лигноуглеводного комплекса, так и целлюлозы соломы с образованием низкомолекулярных трудно удаляемых из ИЖ соединений.

Согласно данным таблицы 1 элементный состав выделенных фракций целлюлозы практически не зависит от температуры и продолжительности обработки.

Выход фракции гемицеллюлозы при продолжительности обработки 1 ч с повышением температуры до $150{ }^{\circ} \mathrm{C}$ возрастает, но остается ниже содержания гемицеллюлозы в исходной соломе (рис. 4). Выход фракции достигает ее содержания в исходной соломе при продолжительности обработки 5 ч $\left(140{ }^{\circ} \mathrm{C}\right)$ и 2 ч $\left(150^{\circ} \mathrm{C}\right)$.

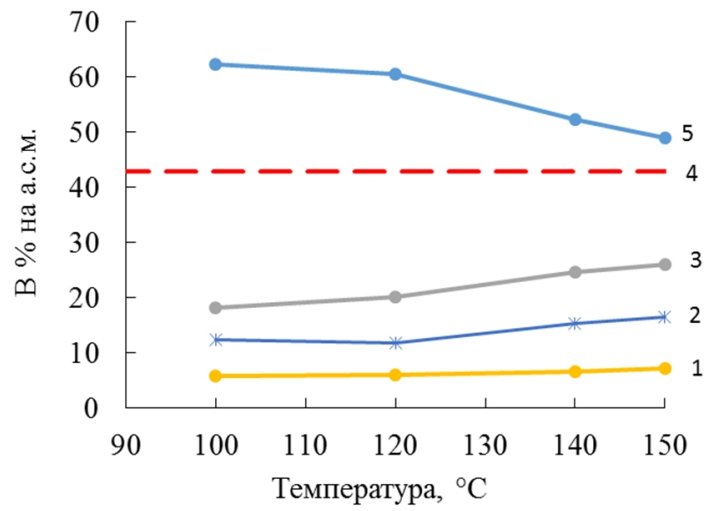

Рис. 2. Зависимость выхода фракций от температуры обработки в течение 1 ч: 1 - фракция лигнина; 2 - убыль биомассы соломы; 3 - фракция гемицеллюлозы; 4 - содержание целлюлозы в исходной соломе; 5 - фракция целлюлозы

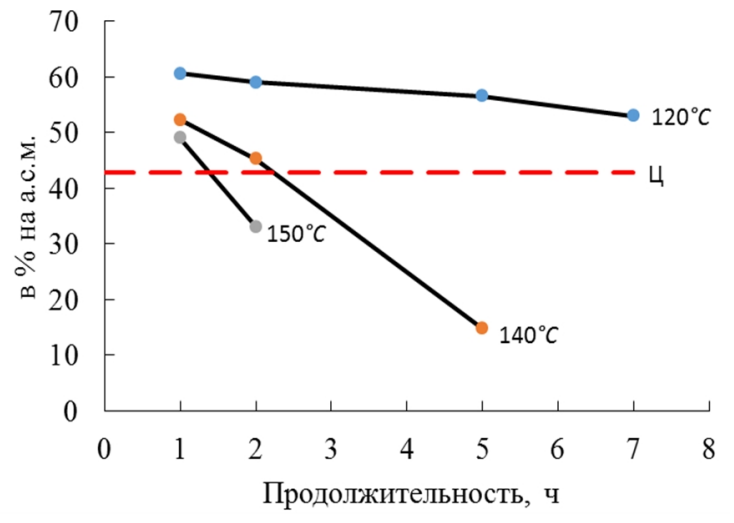

Рис. 3. Зависимость выхода фракции целлюлозы от температуры и продолжительности обработки: Ц - содержание целлюлозы в исходной соломе

Таблица 1. Элементный состав фракций целлюлозы

\begin{tabular}{c|c|c|c|c|c}
\hline \multirow{2}{*}{ Условия обработки* } & \multicolumn{4}{|c|}{ Элементный состав, \% } & \multirow{2}{*}{ Структурная единица } \\
\cline { 2 - 4 } & $\mathrm{C}$ & $\mathrm{H}$ & $\mathrm{N}$ & $\mathrm{O}_{\text {по разн. }}$ & $\mathrm{C}_{6} \mathrm{H}_{10,2} \mathrm{O}_{5,2}$ \\
$100 / 1$ & 43,6 & 6,16 & 0,24 & 50,00 & $\mathrm{C}_{6} \mathrm{H}_{10,1} \mathrm{O}_{5,1}$ \\
$120 / 1$ & 43,75 & 6,11 & 0,24 & 49,89 & $\mathrm{C}_{6} \mathrm{H}_{10,0} \mathrm{O}_{5,1}$ \\
$140 / 1$ & 43,91 & 6,12 & 0,17 & 49,80 & $\mathrm{C}_{6} \mathrm{H}_{10,5} \mathrm{O}_{5,1}$ \\
$150 / 1$ & 43,95 & 6,40 & 0,15 & 49,50 & $\mathrm{C}_{6} \mathrm{H}_{10,3} \mathrm{O}_{5,3}$ \\
\hline $140 / 2$ & 43,17 & 6,16 & 0,21 & 50,404 & \\
\hline
\end{tabular}

* 100/1 - температура $100^{\circ} \mathrm{C}$, продолжительность 1 ч 
При $120{ }^{\circ} \mathrm{C}$ продолжительность обработки практически не влияет на выход фракции лигнина, который составил около $6,5 \%$ на а.с.м. (рис. 5) Процессы делигнификации соломы заметно проявляются при температурах выше $140{ }^{\circ} \mathrm{C}$. Максимальный выход фракции лигнина (около $16 \%$ ) был получен при $140{ }^{\circ} \mathrm{C}$ за 5 ч, а при $150{ }^{\circ} \mathrm{C}-$ за 2 ч обработки, но он был значительно ниже содержания лигнина в исходной соломе. Низкая эффективность извлечения лигнина из лигноцеллюлозы в среде ионной жидкости в отдельной фракции согласуется с результатами, приведенными в [9]. Вероятно это можно объяснить наличием ковалентных связей между структурными фрагментами лигнина и полисахаридов [10].

Элементный состав фракций лигнина (табл. 2) свидетельствует о высоком содержании атомов кислорода в исследуемых образцах, которое с повышением температуры обработки снижается, как и насыщенность компонентов фракции водородом. Можно отметить также повышение содержания атомов углерода с увеличением температуры обработки.

По данным функционального анализа (табл. 3) наиболее представительными во фракциях лигнина являются метоксильные группы. Их содержание во фракциях находится в пределах от 11,8 до $13,9 \%$. Результаты расчета $\mathrm{C}_{9}$-формулы структурного звена фракций лигнинов (табл. 3) показывают, что количество метоксильных групп близко к 1,0 ед/ $\mathrm{C}_{9}$. Возможно, это связано с относительно высоким содержанием в полученных образцах $n$-гидроксифенильных фрагментов. Снижение количества метоксильных групп во фракции, полученной при $150^{\circ} \mathrm{C}$, до 0,71 ед/С 9 может свидетельствовать о протекании реакции деметоксилирования.

Температура обработки не оказывает существенного влияния на содержание фенольных ОН-групп (табл. 3). Их количество составляет 0,6 ед/С 9 и находится в пределах, определенных для органосольвентных лигнинов, выделенных из соломы пшеницы [11].

По карбоксильным группам наблюдается рост содержания с повышением температуры с $0,47 \%$ при $100{ }^{\circ} \mathrm{C}$ до $3,44 \%$ при $150{ }^{\circ} \mathrm{C}$. Согласно проведенным расчетам на 100 атомов углерода фракции лигнина приходится от 2 до 14 карбоксильных групп.

В исследованных условиях обработки соломы ионной жидкостью не удалось добиться полного разделения основных компонентов соломы и выделения их в составе отдельных фракций. Установлено, что в этих условиях процессы делигнификации протекают с высокой эффективностью только на начальной стадии обработки и выделенные фракции целлюлозы и гемицеллюлоз содержат в значительных количествах лигнин.

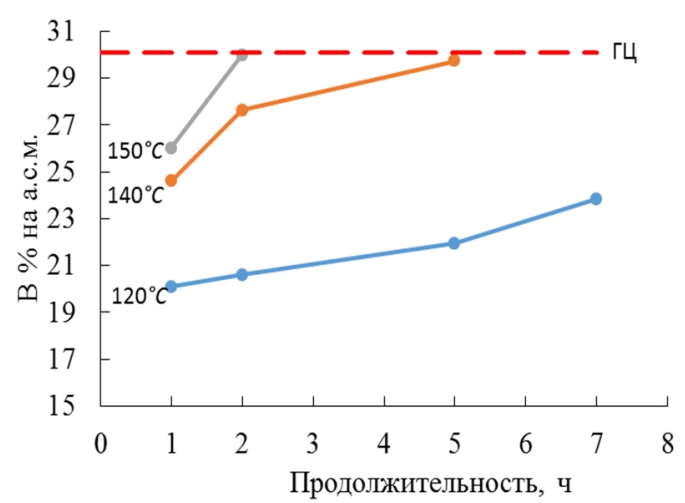

Рис. 4. Зависимость выхода фракции гемицеллюлозы от температуры и продолжительности обработки:

ГЦ - содержание гемицеллюлозы в исходной соломе

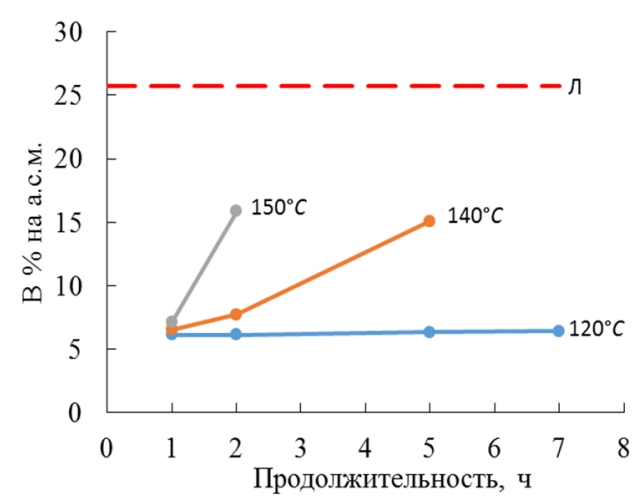

Рис. 5. Зависимость выхода фракции лигнина от температуры и продолжительности обработки: Л - содержание лигнина в исходной соломе

Таблица 2. Элементный состав фракций лигнина

\begin{tabular}{c|c|c|c|c|c}
\hline \multirow{2}{*}{ Условия обработки } & \multicolumn{3}{|c|}{ Элементный состав, \% } & \multirow{2}{*}{ Структурная единица } \\
\cline { 1 - 4 } & $\mathrm{C}$ & $\mathrm{H}$ & $\mathrm{N}$ & $\mathrm{O}$ & \\
\hline $100 / 1$ & 52,56 & 6,43 & 0,29 & 40,71 & $\mathrm{C}_{9} \mathrm{H}_{10,0} \mathrm{O}_{5,2}\left(\mathrm{OCH}_{3}\right)_{0,92}$ \\
$120 / 1$ & 55,42 & 5,91 & 0,4 & 38,28 & $\mathrm{C}_{9} \mathrm{H}_{13,9} \mathrm{O}_{4,7}\left(\mathrm{OCH}_{3}\right)_{0,83}$ \\
$140 / 1$ & 58,82 & 6,35 & 0,47 & 34,32 & $\mathrm{C}_{9} \mathrm{H}_{13,1} \mathrm{O}_{3,9}\left(\mathrm{OCH}_{3}\right)_{0,93}$ \\
$150 / 1$ & 58,06 & 6,73 & 4,2 & 30,99 & $\mathrm{C}_{9} \mathrm{H}_{12,5} \mathrm{O}_{3,6}\left(\mathrm{OCH}_{3}\right)_{0,71}$ \\
$140 / 2$ & 58,85 & 6,41 & 1,88 & 32,83 & $\mathrm{C}_{9} \mathrm{H}_{10,9} \mathrm{O}_{3,8}\left(\mathrm{OCH}_{3}\right)_{0,82}$ \\
\hline
\end{tabular}


Таблица 3. Функциональные группы во фракциях лигнина, \%

\begin{tabular}{c|c|c|c}
\hline Условия обработки & $\mathrm{OH}_{\text {фен }}$ & $\mathrm{OCH}_{3}$ & $\mathrm{COOH}$ \\
\hline $100 / 1$ & 4,7 & 13,9 & 0,47 \\
$120 / 1$ & 5,1 & 13,4 & 0,93 \\
$140 / 1$ & 5,4 & 13,8 & 1,18 \\
$150 / 1$ & 5,4 & 11,8 & 3,44 \\
$140 / 2$ & 5,5 & 13,9 & 1,54 \\
\hline
\end{tabular}

Тем не менее результаты исследования состава выделенных фракций целлюлозы методом ИКспектроскопии (рис. 6) свидетельствуют о нарушении прочности водородных связей в макромолекулах целлюлозы. Об этом можно судить по изменению относительной интегральной интенсивности полосы валентных колебаний ОН-групп $\mathrm{A}_{3400} / \mathrm{A}_{2900}$, где $\mathrm{A}_{2900}$ - интегральная интенсивность полосы при 2900 см характеризующая валентные колебания ОН-, $\mathrm{CH}-$ и $\mathrm{CH}_{2}$ - групп и используемая в качестве внутреннего стандарта. Эта характеристика основана на том, что разрушение водородных связей приводит к уменьшению интенсивности полосы валентных колебаний ОН-групп [12]. Определение интегральной интенсивности полос поглощения при 3400 и $2900 \mathrm{~cm}^{-1}$ проводили с применением метода базисной линии по методике [13]. Согласно полученным данным значение соотношения $\mathrm{A}_{3400} / \mathrm{A}_{2900}$ для образцов целлюлозы, выделенных при повышении температуры обработки, снижается с 6,9 при $100{ }^{\circ} \mathrm{C}$ до 4,1 при $150{ }^{\circ} \mathrm{C}$, что является следствием нарушения водородных связей. Это позволяет предположить, что целлюлоза, обработанная в среде хлорида 1-бутил-3-метилимидазолия в интервале температур $100-150{ }^{\circ} \mathrm{C}$, характеризуется ослабленной сеткой водородных связей, что может повлиять на ее свойства, в частности на реакционную способность в процессе ферментолиза.

Для оценки эффективности предобработки соломы в среде ИЖ был проведен ферментолиз исходной соломы и выделенных фракций целлюлозы и гемицеллюлозы. Полученные результаты приведены на рисунке 7. Выходы редуцирующих веществ после ферментолиза исходной соломы при 4 и 48 ч составил 6,3 и 11,5\% соответственно. Обработка соломы в среде ИЖ в исследуемом интервале температур повышает выход сахаров из фракции целлюлозы при четырехчасовом ферментолизе в 4-5 раз. При ферментолизе 48 ч он составил уже 52,6\% для фракции целлюлозы, полученной при $100{ }^{\circ} \mathrm{C}$, и 72,2\% - для полученной при $150{ }^{\circ} \mathrm{C}$.

Степень ферментолиза фракций гемицеллюлоз, которые относят к легко гидролизуемым полисахаридам, независимо от температуры и продолжительности обработки соломы в ИЖ выше, чем у выделенных в этих же условиях фракций целлюлозы. Для фракции гемицеллюлозы, выделенной при $120{ }^{\circ} \mathrm{C}(1$ ч), она составила $16,8 \%$ и с повышением температуры до $150{ }^{\circ} \mathrm{C}$ практически не изменилась. Максимальный выход сахаров из фракции гемицеллюлозы, составивший 23,2\% на а.с.м. соломы, получен при $140{ }^{\circ} \mathrm{C}$ (2 ч) (рис. 7).

Высокий выход сахаров из выделенных фракций целлюлозы получен после обработки соломы при температурах до $120^{\circ} \mathrm{C}$. Несмотря на снижение выхода фракции целлюлозы с повышением температуры и продолжительности обработки выход сахаров немного повышается, достигая максимального значения $37,6 \%$ на а.с.м. соломы или 82,95\% на фракцию при $140{ }^{\circ} \mathrm{C}$ и продолжительности обработки 2 ч. Наибольший выход сахаров из полисахаридов соломы пшеницы (60,8\% на а.с.м.) получен после ее обработки в среде хлорида 1-бутил-3-метилимидазолия при $140{ }^{\circ} \mathrm{C}$ в течение 2 ч.

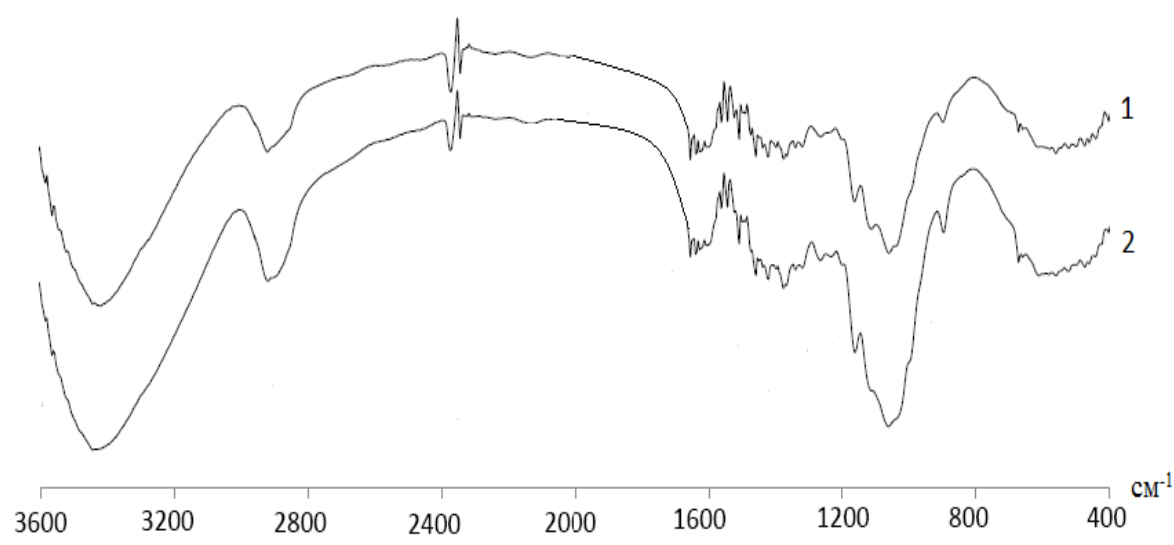

Рис. 6. ИК-спектры фракций: 1 - целлюлоза при $100{ }^{\circ} \mathrm{C}, 2$ - целлюлоза при $150{ }^{\circ} \mathrm{C}$ 
Рис. 7. Зависимость выхода редуцирующих веществ при ферментолизе фракций целлюлозы и гемицеллюлозы от температуры и продолжительности обработки: 100/1 - фракции, полученные после обработки при $100{ }^{\circ} \mathrm{C}$ в течение 1 ч

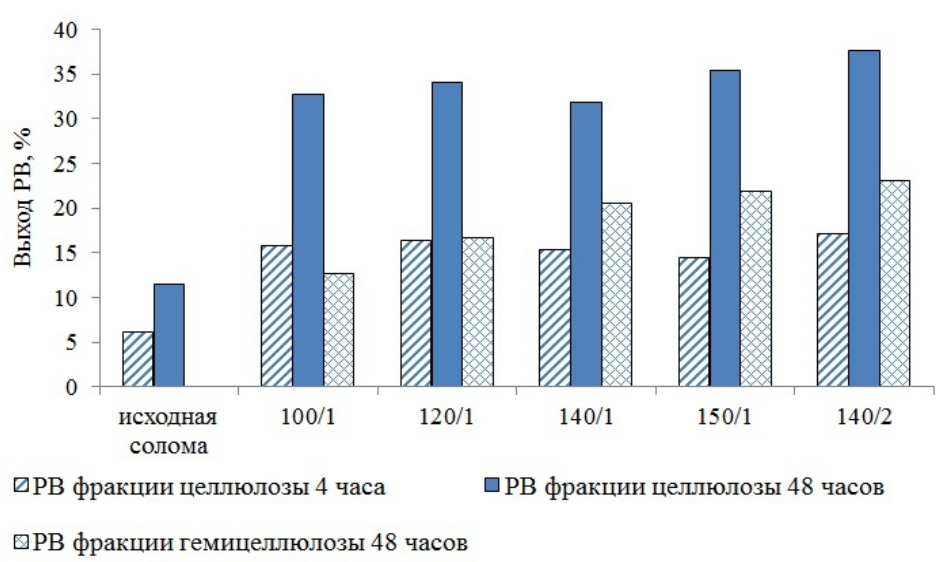

\section{Выводы}

В результате выполненного исследования показана возможность использования обработки соломы пшеницы в среде хлорида 1-бутил-3-метилимидазолия для фракционирования ее биомассы на отдельные групповые компоненты и повышения реакционной способности в условиях ферментолиза. Но в исследованных условиях обработки не удалось добиться полного разделения основных компонентов соломы и выделения их в составе отдельных фракций.

Установлено, что повышение продолжительности и температуры обработки в интервале $100-150{ }^{\circ} \mathrm{C}$ способствует разрушению лигноцеллюлозного комплекса соломы и выделению фракций основных компонентов. Наиболее эффективно это для фракций полисахаридов. Низкий выход фракции лигнина может быть связан с наличием химических связей между структурными фрагментами лигнина и полисахаридов, устойчивых в условиях обработки в среде хлорида 1-бутил-3-метилимидазолия.

С повышением температуры обработки происходит очистка целлюлозы от гемицеллюлоз и лигнина. Выявлено, что процессы делигнификации достаточно интенсивно протекают при температурах до $120{ }^{\circ} \mathrm{C}$. В составе фракции целлюлозы содержание лигнина снижается до 17-18\% и нарушается прочность водородных связей в макромолекулах целлюлозы. Все это в комплексе приводит к повышению реакционной способности целлюлозы в условиях ферментолиза. В сравнении с исходной соломой она возрастает в зависимости от условий обработки в 5-7 раз.

Максимальный выход сахаров из полисахаридов соломы пшеницы (60,8\% на а.с.м.) получен после ее обработки в среде хлорида 1-бутил-3-метилимидазолия при $140{ }^{\circ} \mathrm{C}$ в течение 2 ч.

\section{Список литературы}

1. Tan S.S.Y., Macfarlane D.R. Ionic liquids in biomass processing // Top Curr Chem. 2010. Vol. 290. Pp. 311-339.

2. Swatloski R.P., Spear S.K., Holbrey J.D., Rogers R.D. Dissolution Cellulose with Ionic Liquids // J. Am. Chem. Soc. 2002. Vol. 124. Pp. 4974-4975.

3. Zhang H., Wu J., Zhang J., He J. 1-Allyl-3-methylimidazolium Chloride Room Temperature Ionic Liquid: A New and Powerful Nonderivatizing Solvent for Cellulose // Macromolecules. 2005. Vol. 3. N20. Pp. 8272-8277.

4. Gericke M., Fardim P., Heinze T. Ionic liquids - Promising but challenging solvents for homogeneous derivatization of cellulose // Molecules. 2012. Vol. 17. Pp.7458-7502.

5. Da Costa Lopes A.M., Joao K.G., Rubik D.F., Bogel-Lukasik E., Duarte L.C., Andreaus J., Bogel-Lukasik R. Pretreatment of lignocellulose biomass using ionic liquids: Wheat straw fractionation // Bioresour. Technol. 2013. Vol. 142. Pp. 198-208.

6. Zhang Zhi-guo, Chen Hong-zhang. Enhancement of the enzymatic hydrolysis of wheat straw by pretreatment with 1-allyl-3-methylimidazolium chloride $([\mathrm{Amim}] \mathrm{Cl}) / /$ African Journal of Biotechnology April, 2012. Vol. 11. N31. Pp. 8032-8037.

7. Dubois M., Gilles K.A. Colorimetric method for determination of sugars and related substances // Analyt. Chem. 1956. Vol. 28. Pp. 350-356.

8. Закис Г.Ф. Функциональный анализ лигнинов и их производных. Рига: Знание, 1987. 230 с.

9. Haseth J.K. Decrystallization of lignocellulose biomass using ionic liquids: Master thesis. NTNU, 2012. 85 p.

10. Faulon J., Carlson G.A., Hatcher P.G. A three-dimensional model for lignocellulose from gymnospermous wood // Organic Geochemistry. 1994. Vol. 21. Pp. 1169-1179. 
11. Lora J.H., Glasser W.G. Resent industrial application of lignin: A sustainable alternative to nonrenewable materials // J. of Polym. and the Environment. 2002. Vol. 10. N1/2. Pp. 39-48.

12. Пиментел Д., Мак-Клелан О. Водородная связь. М., 1964. 462 с.

13. Карливан В.П. Методы исследования целлюлозы. Рига, 1981. 257 с.

Поступило в редакииюю 25 мая 2016 г.

После переработки 10 июня 2016 г.

Evstaf'ev S.N.*, Khoang K.K. INFLUENCE OF PROCESSING CONDITIONS ON OUTPUT AND PRODUCT COMPOSITION OF WHEAT STRAW FRACTIONATION IN MEDIUM 1-BUTYL-3-METHYLIMIDAZOLIUM CHLORIDE

Irkutsk National Research Technical University, ul. Lermontova, 83, Irkutsk, 664074 (Russia), e-mail: esn@istu.edu

The work is devoted to identifying the influence of temperature and duration of wheat straw treatment in the environment chloride 1-butyl-3-methylimidazolium on outputs and composition of the fractions of its main components. It is found that with increasing treatment temperature and duration in the range $100-150{ }^{\circ} \mathrm{C}$ cellulose purification occurs by hemicelluloses and lignin. It was revealed that delignification processes occur quite rapidly at $120^{\circ} \mathrm{C}$. As part of the cellulose, fraction of lignin content is reduced to $17-18 \%$, and the strength of hydrogen bonds is broken. All this together it leads to significantly increase the reaction capability cellulose in conditions of enzymatic hydrolysis.

The maximum yield of sugars from polysaccharides of wheat straw $(60,8 \%$ on the A.S.M.) is obtained after the treatment in a medium chloride 1-butyl-3-methylimidazolium at $140{ }^{\circ} \mathrm{C}$ for $2 \mathrm{~h}$.

Keywords: wheat straw, ionic liquid, 1-butyl-3-methylimidazolium chloride, cellulose, hemicellulose, lignin, IR spectroscopy.

\section{References}

1. Tan S.S.Y., Macfarlane D.R. Top Curr Chem., 2010, vol. 290, pp. 311-339.

2. Swatloski R.P., Spear S.K., Holbrey J.D., Rogers R.D. J. Am. Chem. Soc., 2002, vol. 124, pp. $4974-4975$.

3. Zhang H., Wu J., Zhang J., He J. Macromolecules, 2005, vol. 3, no. 20, pp. 8272-8277.

4. Gericke M., Fardim P., Heinze T. Molecules, 2012, vol. 17, pp.7458-7502.

5. Da Costa Lopes A.M., Joao K.G., Rubik D.F., Bogel-Lukasik E., Duarte L.C., Andreaus J., Bogel-Lukasik R. Bioresour. Technol., 2013, vol. 142, pp. 198-208.

6. Zhang Zhi-guo, Chen Hong-zhang. African Journal of Biotechnology, 2012, vol. 11, no. 31, pp. 8032-8037.

7. Dubois M., Gilles K.A. Analyt. Chem., 1956, vol. 28, pp. 350-356.

8. Zakis G.F. Funktsional'nyi analiz ligninov $i$ ikh proizvodnykh. [Functional analysis of lignins and their derivatives]. Riga, 1987, 230 p. (in Russ.).

9. Haseth J.K. Decrystallization of lignocellulose biomass using ionic liquids: Master thesis. NTNU, 2012. 85 p.

10. Faulon J., Carlson G.A., Hatcher P.G. Organic Geochemistry, 1994, vol. 21, pp. 1169-1179.

11. Lora J.H., Glasser W.G. J. of Polym. and the Environment, 2002, vol. 10, no. 1/2, pp. 39-48.

12. Pimentel D., Mak-Klelan O. Vodorodnaia sviaz'. [Hydrogen bond]. Moscow, 1964, 462 p. (in Russ.).

13. Karlivan V.P. Metody issledovaniia tselliulozy. [Methods of cellulose research]. Riga, 1981, 257 p. (in Russ.).

Received May 25, 2016

Revised June 10, 2016

\footnotetext{
* Corresponding author.
} 